\title{
Optimization Model for Headway of a Suburban Bus Route
}

\author{
Xiaohong Jiang, ${ }^{1}$ Xiucheng Guo, ${ }^{1}$ and Bin $\operatorname{Ran}^{2}$ \\ ${ }^{1}$ Transportation College, Southeast University, 2 Sipailou, Nanjing, Jiangsu 210096, China \\ ${ }^{2}$ Department of Civil and Environmental Engineering, University of Wisconsin-Madison, Madison, WI 53706, USA
}

Correspondence should be addressed to Xiucheng Guo; seuguo@163.com

Received 25 July 2014; Revised 29 August 2014; Accepted 14 September 2014; Published 30 September 2014

Academic Editor: Huimin Niu

Copyright (C) 2014 Xiaohong Jiang et al. This is an open access article distributed under the Creative Commons Attribution License, which permits unrestricted use, distribution, and reproduction in any medium, provided the original work is properly cited.

\begin{abstract}
Due to relatively low passenger demand, headways of suburban bus route are usually longer than those of urban bus route. Actually it is also difficult to balance the benefits between passengers and operators, subject to the service standards from the government. Hence the headway of a suburban bus route is usually determined on the empirical experience of transport planners. To cope with this problem, this paper proposes an optimization model for designing the headways of suburban bus routes by minimizing the operating and user costs. The user costs take into account both the waiting time cost and the crowding cost. The feasibility and validity of the proposed model are shown by applying it to the Route 206 in Jiangning district, Nanjing city of China. Weightages of passengers' cost and operating cost are further discussed, considering different passenger flows. It is found that the headway and objective function are affected by the weightages largely.
\end{abstract}

\section{Introduction}

"Suburban" here is termed as the nonmetropolitan areas outside the territory of any incorporated or unincorporated city, town, or village. Traditionally, the suburban bus routes are operated in the region between the city and rural areas, commuting on the urban roads and highways, with fixed routes and a unique route number/name. Usually only fewer trunk suburban bus routes are operated in rural areas, so the trunk route is very important for residents of rural areas. The trunk suburban bus routes with stable passenger flows operate similarly with urban bus routes as discussed by Cook et al. [1]. This paper focuses on the headway design of trunk bus routes.

There are a number of studies on the headway design of bus route. Vuchic [2] proposed the method of maximum load section (MLS), aiming to support enough vehicle capacity for the maximum load section. Furth and Wilson [3] mentioned four common approaches for determining the headways. Ceder $[4,5]$ proposed four formulas based on 16 countries' practices in Europe, using the method of MLS. Koutsopoulos et al. [6] developed a programming problem for determining frequencies in a transit network with a demand that varies along daily periods. LeBlanc [7] introduced a model for determining frequencies, using a modal-split assignment programming model with distinct transit routes. Banks [8] presented a model for setting headways in a transit-route system. Wirasinghe [9] examined the validity of a traditional method, formulated by Newell, for determining frequencies. Larsen and Sunde [10], Chang and Hsu [11], and Luethi et al. [12] discussed the waiting time. And some robust optimization models of schedule design for a fixed bus route were discussed elsewhere [13-15].

The objective function proposed by exciting studies focused on minimizing the operating cost and passengers' waiting time cost. Uncomfortability due to crowding in vehicle is usually neglected. As a matter of fact, passengers of suburban bus routes always carry many large items, such as farm products and devices, which occupy large room area per person and make passengers feel crowded. It is necessary to consider the additional crowding cost, as discussed by $\mathrm{Li}$ et al. [16]. TCRP report 100 [17] proposed the LOS thresholds for passenger load.

Moreover, how to determine the weightages of the passengers' cost and the bus company's operating cost of suburban bus routes is also a complex problem. The passenger flow decreases from downtown to townships and villages. Generally, bus companies are unwilling to operate the routes with low ridership, and they always expect a longer headway 
to reduce operating costs. In contrast, passengers expect more efficient service (i.e., high frequency) to reduce the waiting time. In addition, transit administrators require operators to engage in suburban bus routes and offer basic service for passengers, in order to increase area coverage and frequency. Therefore, it is necessary to discuss the cost weightages of the passengers and the bus company.

Hence, the optimization model is to reach the minimization of the total costs, including the waiting time cost, the uncomfortability due to crowding in vehicle, and the operating cost of bus companies. Genetic algorithm is used to calculate the model. Finally, a case study is taken to further testify the applicability and feasibility of this model. The weightages of passengers' cost and bus company's operating cost are also discussed, considering different passenger flows.

\section{Mathematical Model}

2.1. Notation and Assumptions. The proposed model is developed based on a dedicated suburban bus route. The trip demand is assumed to be constant and known. Arrival of passengers at the bus stop is considered to be random. The waiting time that passengers are willing to bear is not long. Assume that the value of trip time for each passenger is the same, and all buses on the road drive at the same average speed. Occasional accidents that might be caused by traffic congestion will not be considered. All buses are not allowed to overtake and skip stops.

For the sake of presentation, the following notations are introduced:

$i$ : optimization time period, $i=1,2, \ldots, l$,

$j$ : bus stop of bus line, $j=1,2, \ldots, m$,

$H_{i}$ : headway during the optimization time period $i$,

$T_{i}$ : length of the optimization time period $i$,

$q_{i j}$ : number of passengers boarding at stop $j$ during time period $i$,

$Q_{i j}$ : number of passengers in vehicle at stop $j$ during time period $i$

$S_{s i j}$ : standing area per person.

2.2. Total Costs. The total costs include the costs of passengers and bus companies. The passengers' costs consist of waiting time cost at the bus stop and uncomfortability cost in vehicle.

2.2.1. Waiting Time Cost. Waiting time cost depends on the interval between consecutive vehicles. Ceder [4] gave the formula of waiting time during the optimization time period $i$ :

$$
\mathrm{WT}_{i j}=\frac{H_{i}^{2}+\sigma^{2}}{2 H_{i}},
$$

where $\mathrm{WT}_{i j}$ is the waiting time at the stop $j . \sigma$ is the deviation factor related with operation reliability. In rural areas, highway impedance rarely happens. The value of $\sigma$ is 0 . The average waiting time can be assumed to be half of the headway.
Assume $c_{w}$ is the value of waiting time for one passenger. The waiting time cost of all bus stops could be expressed as follows:

$$
W=c_{w} \sum_{i=1}^{l} \sum_{j=1}^{m} q_{i j} \cdot \frac{H_{i}}{2} .
$$

2.2.2. Crowding Cost in Vehicle. Because of large items carried by passengers, the uncomfortability for crowding in vehicle is considered as additional trip cost. The cost for crowding in vehicle is determined by LOS thresholds for passenger load. The standing passenger area is used to reflect LOS. According to "Transit Capacity and Quality of Service Manual" [17], the LOS thresholds for passenger load and crowding cost per person are shown in Table 1 . by

The total cost for crowding in vehicle could be calculated

$$
\begin{aligned}
& Y=c_{y} \sum_{i=1}^{l} \sum_{j=1}^{m} Q_{i j}, \\
& c_{y}= \begin{cases}0, & S_{s i j}>1.00 \\
2, & 0.76<S_{s i j}<1.00 \\
4, & 0.51<S_{s i j}<0.75 \\
8, & 0.36<S_{s i j}<0.50 \\
16, & 0.20<S_{s i j}<0.35 \\
32, & S_{s i j}<0.20,\end{cases}
\end{aligned}
$$

$$
\text { where } S_{s i j}=\frac{S_{w s}}{(1+a) \cdot Q_{i j} \cdot\left(H_{i} / 60\right)-N^{\prime}} \text {, }
$$

where $S_{w s}$ is the total standing area in vehicle. $N^{\prime}$ is the number of seat. Using the factor $a$, the additional occupied room of large items is converted in terms of number of passengers.

2.2.3. Bus Company's Operating Cost. For rural bus routes, the bus company's operating cost is always more than operating benefit. Hence, the operation profit is a negative value. Here, the operating deficit is taken to express the value of operation. Supposing the operating cost per cycle is $c_{c}$ and the operating benefit per passenger is $c_{s}$, the operation deficit could be calculated as

$$
D=c_{c} \sum_{i=1}^{l} \frac{T_{i}}{H_{i}}-c_{s} \sum_{i=1}^{l} \sum_{j=1}^{m} q_{i j}
$$

2.3. Normalization of Target Variables. The dimensions of the passenger waiting time cost, crowding cost in vehicle, and bus operating deficit are different. Hence, three cost variables are normalized by linear function transformation as follows:

$$
X^{*}=\frac{X-\text { Min Value }}{\text { Max Value }- \text { Min Value }} .
$$

The maximum waiting time cost $W_{\max }$ and minimum waiting time cost $W_{\text {min }}$ can be calculated based on the maximum headway and minimum headway, respectively. 
TABLE 1: Passenger load LOS and crowding cost of suburban bus routes.

\begin{tabular}{lccl}
\hline LOS Standing passenger area $\left(\mathrm{m}^{2} /\right.$ person) & Crowding cost in vehicle per person $(\mathrm{RMB} / \mathrm{person})$ & Comments \\
\hline $\mathrm{A}$ & $>1.00$ & 0 & No passenger needs to sit next to another \\
$\mathrm{B}$ & $0.76 \sim 1.00$ & 2 & Passengers can choose where to sit \\
$\mathrm{C}$ & $0.51 \sim 0.75$ & 4 & All passengers can sit \\
$\mathrm{D}$ & $0.36 \sim 0.50$ & 8 & Comfortable standee load for design \\
$\mathrm{E}$ & $0.20 \sim 0.35$ & 16 & Maximum schedule load \\
$\mathrm{F}$ & $<0.20$ & 32 & Crush load \\
\hline
\end{tabular}

At LOS "A" load levels, passengers are able to spread out and can use empty seats to store parcels and bags rather than carry them on their laps, while at LOS "E," a bus vehicle is full, and passengers could normally tolerate the full vehicle. LOS "F" represents crush loading levels. Hence, the crowding cost per person, denoted by $c_{y}$, varies from 0 to 32 , when LOS decreases from "A" to "F."

The maximum crowding cost $Y_{\max }$ and minimum crowding cost $Y_{\min }$ can be calculated based on the minimum and maximum standing area per person, respectively.

$D_{\min }$ and $D_{\max }$ are defined as the reasonable ranges of operation deficit for bus companies.

2.4. Objective Function. For a multiobjective optimization problem, converting it to a single objective model is commonly used in the literature. The objective function for this model is the sum of the three cost items, namely, the operation deficit severity, evaluation value of passenger waiting time cost, and crowding cost, respectively:

$$
\begin{aligned}
\min I= & \min \left[\alpha D^{*}+\beta W^{*}+(1-\alpha-\beta) Y^{*}\right], \\
\text { S.t. } & H_{i \min }<H_{i}<H_{i \max }\left(H_{i} \text {-integer }\right),
\end{aligned}
$$

where $D^{*}, W^{*}$, and $Y^{*}$ are the normalized values of each cost variable. $\alpha$ and $\beta$ are the nonnegative weightages which could be adjusted for different bus routes with different passenger demand. Since transit administrators require operators to engage in suburban bus routes to increase area coverage and frequency, the average headway should not be higher than the maximum value. Also, the minimum headway is determined by passenger flow.

2.5. Solution Algorithm. The proposed minimization model is a mixed nonlinear integer programming model. The objective function is not convex or concave, which is a NP-hard problem and difficult to be solved by any exact algorithm. Thus, according to the existing studies by Goldberg [18], Chambers [19] and Liu and Meng [20], a Genetic Algorithm is used to solve the model.

\section{Case Study}

3.1. Data. Route 206 is in Jiangning district, and it connects the center of Jiangning district and Hushu Township. It is 21 kilometers long with 28 bus stops. The demand of boarding passengers and passengers in vehicle at each stop along the day are investigated and known. The passenger flows of Route 206 during each time period are shown in Figure 1.

As the maximum demand of boarding/alighting passenger is only 220 passengers/hour, the minimum headway is set as 2 minutes. The maximum headway is 30 minutes followed

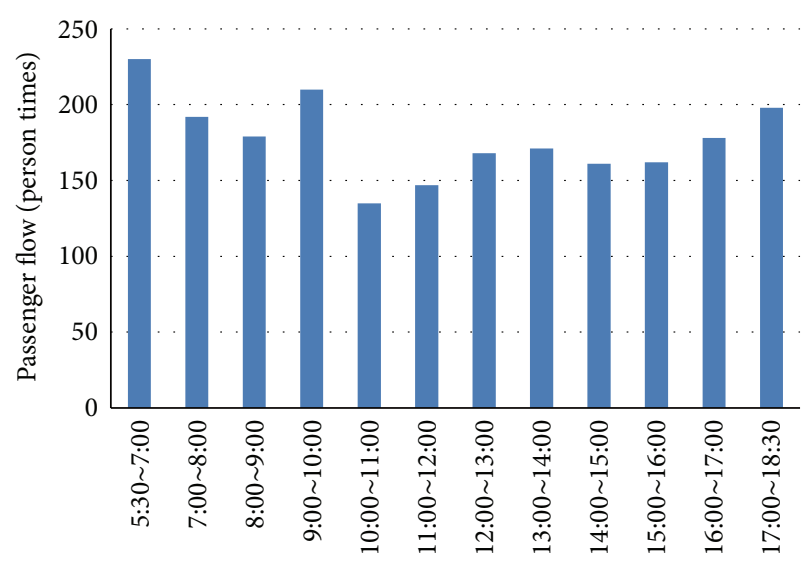

FIgURE 1: Passenger flow of Route 206 along the day.

by the administrators' requirement. The operation time is divided into 12 time periods. The upper limit of operating deficit is $10,000 \mathrm{RMB} . c_{w}$ is $0.5 \mathrm{RMB} / \mathrm{min} . c_{c}$ is $2 \mathrm{RMB} . c_{s}$ is $150 \mathrm{RMB} /$ cycle.

3.2. Results. A Genetic Algorithm is used to solve the model. Generate 100 individuals randomly as the initial population. Set the maxim generation numbers as 500 , elite count as 10 , crossover fraction as 0.8 , and fitness function as $l e-100$. The algorithm is calculated by the "Genetic Algorithm and Direct Search Toolbox" of Matlab 2012(b) and implemented on a personal computer with Inter Core i5-3470 CPU @ 3.20 GHz, 3.20 GHz and 4.00 G RAM. A convergence trend of the solution algorithm can be clearly seen from Figure 2 .

3.2.1. Sensitivity Analysis for Different Weightages. Figure 3 compares the optimal headways and objective function values of different weightages. With relative importance of passengers' costs growing, the average headways decline; the objective function values also decline, except the case when $\alpha$ is 0.6 . When $\alpha$ is 0.6 , the average headway is highest, while the relative importance of passengers' cost is low. Thus, the optimal headway is confirmed when $\alpha$ is 0.2 .

3.2.2. Sensitivity Analysis with Different Passenger Flows. The following section focuses on how to determine the weightages 


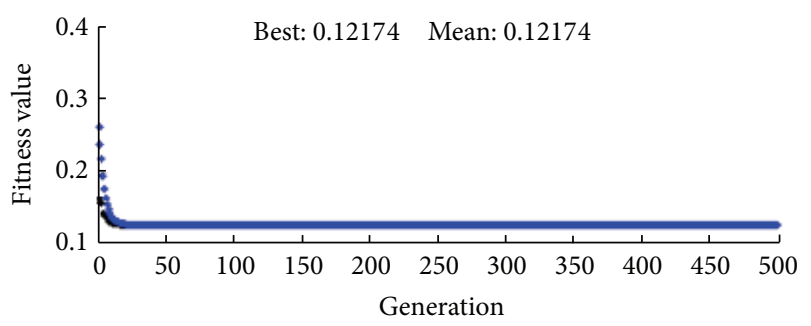

- Best fitness

- Mean fitness

FIGURE 2: Convergence trend of the solution algorithm.

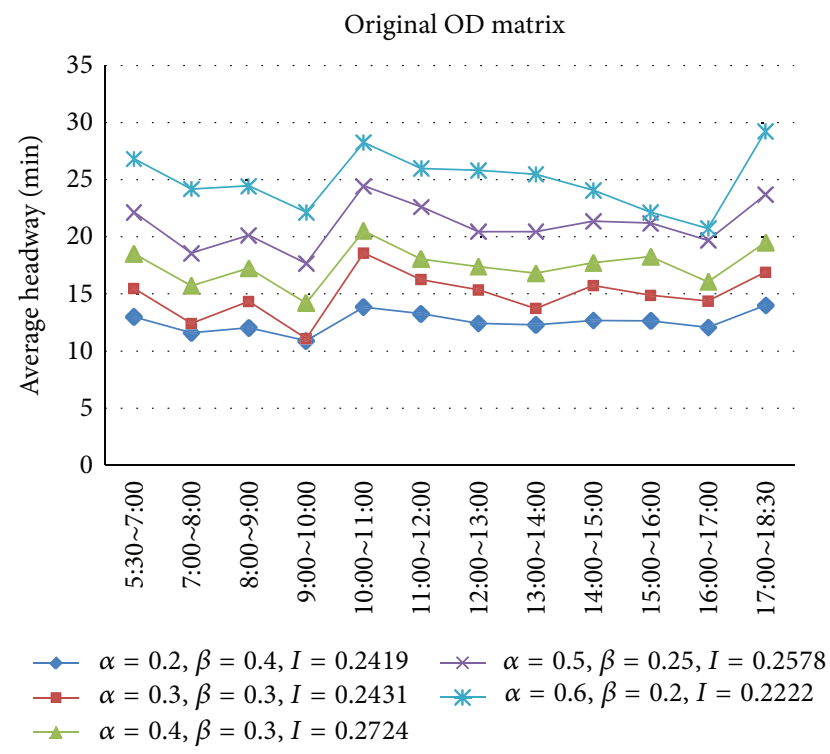

Figure 3: Optimal headways and objective function values with different weightages.

of operating cost and passengers' cost, considering different passenger flows.

Figures 4 and 5 show the optimal headways and objective function values of different weightages when passenger flows increase to 1.5 times and 2 times, respectively. Here, the upper limits of operation deficit increase to $15,000 \mathrm{RMB}$ and 20,000 RMB, respectively. Obviously, average headways decline with the passenger flow growing. The lowest average headway declines from 11 minutes to 5 minutes. Besides, the average headway declines when the relative importance of passengers' cost grows, which indicates the same trend shown in Figure 3.

Figure 6 contains a sensitivity analysis of objective function values with different weightages of operating cost and passengers' cost and different passenger flows. The case with a factor of 1 is used as the benchmark. A weightage greater (less) than 1 means either that operating costs are higher (lower) or passengers' costs are lower (higher) than those assumed in the benchmark. Results displayed in Figure 5 suggest that the more dominant are operating costs, the more optimized are the objective function values. Here passengers' cost should be

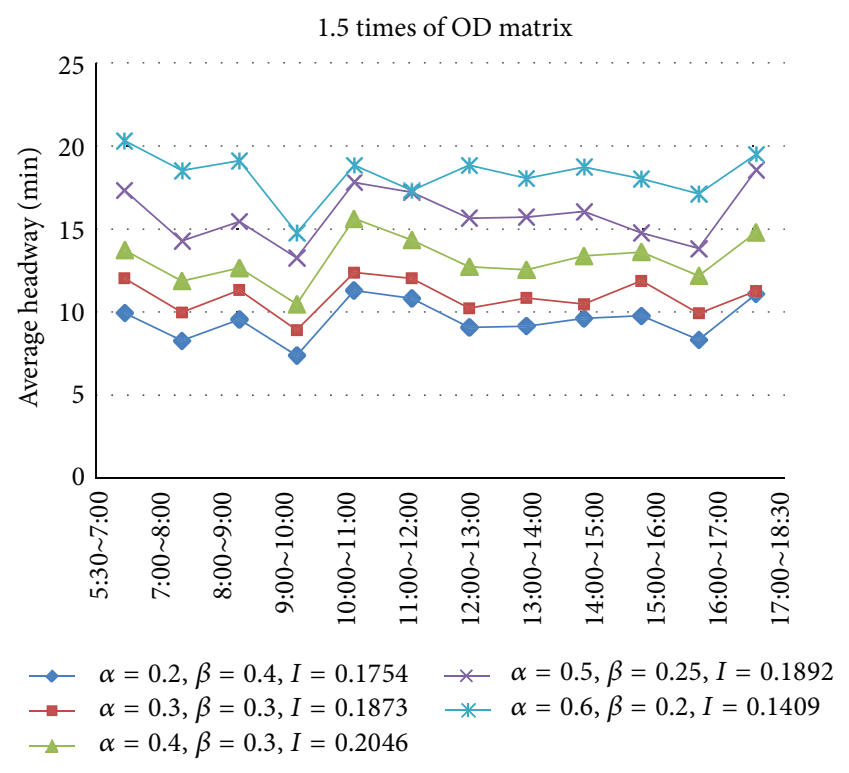

FIGURE 4: Sensitivity analysis of 1.5 times of OD matrix.

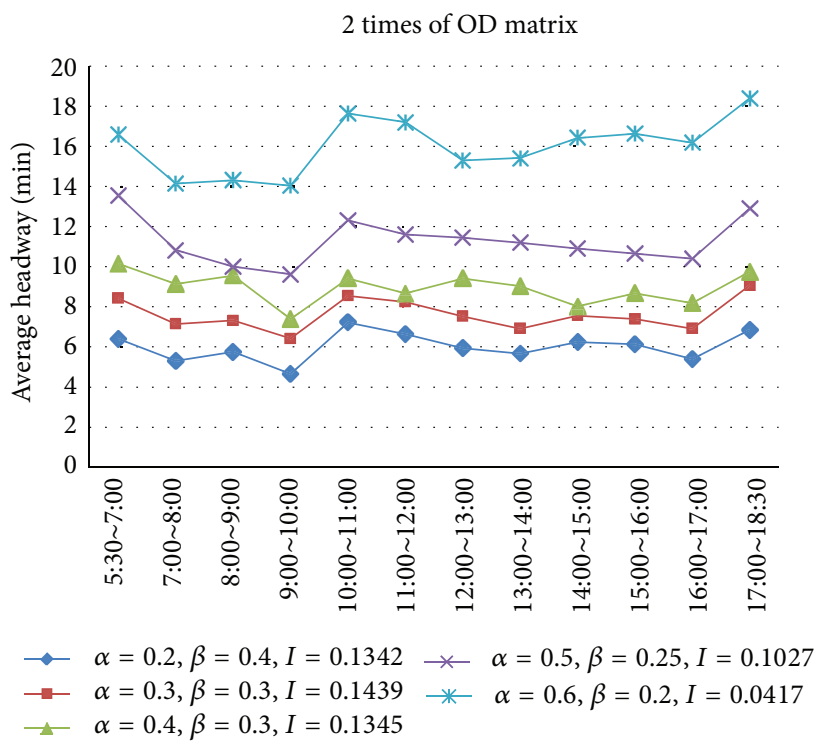

FIGURE 5: Sensitivity analysis of 2 times of OD matrix.

thought higher. Moreover, when $\alpha$ is 0.2 , all of the optimal headways are confirmed for the 1.5 times and 2 times of OD matrix. The average headways and three evaluation values are shown in Table 2. It is seen that the evaluation values of crowding costs are close to zero, due to the low passenger flow and few passengers' need to stand in vehicle.

\section{Conclusions}

The headway design problem for the trunk routes of suburban bus was addressed. A multiobjective optimization model was proposed. The objective is to minimize the weighted sum of operating cost, passengers' waiting time cost, and crowding 
TABLE 2: Optimization headway and evaluation values of original OD, 1.5 times OD, and 2 times OD.

\begin{tabular}{|c|c|c|c|c|c|c|c|c|c|}
\hline \multirow{2}{*}{ Passenger flows } & \multirow{2}{*}{ Weightages } & \multicolumn{8}{|c|}{ Time period } \\
\hline & & $5: 30 \sim 7: 00$ & 7:00 8:00 & 8:00 9:00 & 9:00 10:00 & 10:00 11:00 & $11: 00 \sim 12: 00$ & $12: 00 \sim 13: 00$ & 13:00 14:00 \\
\hline Original & $\alpha=0.2, \beta=0.4$ & 13 & 12 & 12 & 11 & 14 & 13 & 12 & 12 \\
\hline 1.5 times & $\alpha=0.2, \beta=0.4$ & 10 & 8 & 10 & 7 & 11 & 11 & 9 & 9 \\
\hline 2 times & $\alpha=0.2, \beta=0.4$ & 6 & 5 & 6 & 5 & 7 & 7 & 6 & 6 \\
\hline \multirow{2}{*}{ Passenger flows } & \multirow{2}{*}{ Weightages } & \multicolumn{4}{|c|}{ Time period } & $I$ & $D^{*}$ & $W^{*}$ & $Y^{*}$ \\
\hline & & $14: 00 \sim 15: 00$ & 15:00 16:00 & $16: 00 \sim 17: 00$ & $17: 00 \sim 18: 30$ & & $D$ & $v$ & $I$ \\
\hline original & $\alpha=0.2, \beta=0.4$ & 13 & 13 & 12 & 14 & 0.2419 & 0.5043 & 0.3526 & 0 \\
\hline 1.5 times & $\alpha=0.2, \beta=0.4$ & 10 & 10 & 8 & 11 & 0.175 & 0.3975 & 0.2394 & 0.0005 \\
\hline 2 times & $\alpha=0.2, \beta=0.4$ & 6 & 6 & 5 & 7 & 0.1342 & 0.3384 & 0.1102 & 0.056 \\
\hline
\end{tabular}

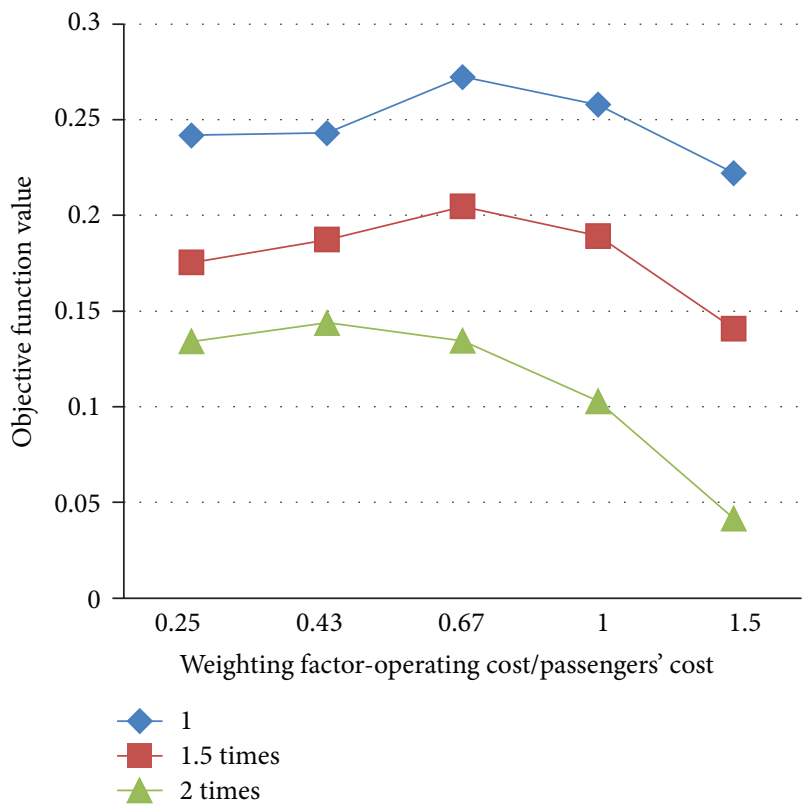

FIGURE 6: Sensitivity analysis of operating cost/passengers' cost.

cost. The crowding cost is calculated by standing passenger area. A case study of Route 206 is taken to testify the feasibility of the proposed methodology. The objective function values decline with passenger flow growing. As the relative importance of costs of passengers grows, the average headway declines. The more dominant is the operating cost, the more optimized is the objective function value. For all of the optimal headways for the original OD matrix, 1.5 times and 2 times of OD matrix are confirmed when $\alpha$ is 0.2 . This model is very helpful in determining the headway of trunk bus routes of suburban transit. The cost for crowding in vehicle is used to evaluate the comfortability. In this case study, the costs for crowding in vehicle are close to zero because of relatively low passenger flow. This variable has a little impact on evaluating passengers' cost. Thus, more data of passenger flows of suburban bus routes should be collected to modify the parameter of crowding cost.

\section{Conflict of Interests}

The authors declare that there is no conflict of interests regarding the publication of this paper.

\section{Acknowledgments}

This research is supported by National Basic Research Program of China (973 Program) (Grant no. 2012CB725405), the Planning Program of Science and Technology of Ministry of Housing and Urban-Rural Development of China (Grant no. 2008-K5-14), Transportation Research Program of Science and Technology of Jiangsu Province (Grant no. 09R02), and 2011 Jiangsu Province College Graduate Research and Innovation Project.

\section{References}

[1] T. J. Cook, J. J. Lawrie, and A. J. Henry, "From rural singlecounty to multicounty regional transit systems: benefits of consolidation," Transportation Research Record, vol. 1841, no. 1, pp. 54-61, 2003.

[2] V. R. Vuchic, Transit Operating Manual, Department of Transportation, University of Pennsylvania, Philadelphia, Pa, USA, 1976.

[3] P. G. Furth and N. H. M. Wilson, "Setting frequencies on bus routes: theory and practice," Transportation Research Record, vol. 818, pp. 1-7, 1981.

[4] A. Ceder, "Bus frequency determination using passenger count data," Transportation Research Part A, vol. 18, no. 5-6, pp. 439453, 1984.

[5] A. Ceder, "Computer application for determining bus headways and timetables," Transportation Research Record, pp. 76-87, 1984.

[6] H. N. Koutsopoulos, A. R. Odoni, and H. M. Nigel, "Determination of headways as a function of time varying characteristics on a transit network," in Computer Scheduling of Public Transport, pp. 391-413, North-Holland, Elsevier Science, 1985.

[7] L. J. LeBlanc, “Transit system network design," Transportation Research, vol. 22, no. 5, pp. 383-390, 1988.

[8] J. H. Banks, "Optimal headways for multi-route transit systems," Journal of Advanced Transportation, vol. 24, no. 2, pp. 127-154, 1990. 
[9] S. C. Wirasinghe, "Initial planning for urban transit systems," in Advanced Modeling for Transit Operations and Service Planning, Elsevier Science, Oxford, UK, 2003.

[10] O. I. Larsen and $\varnothing$. Sunde, "Waiting time and the role and value of information in scheduled transport," Research in Transportation Economics, vol. 23, no. 1, pp. 41-52, 2008.

[11] J. Chang and C. L. Hsu, "The modeling of passenger waiting time for an intermodal transit station," in Proceedings of the 80th Annual Meeting of the Transportation Research Board, 2001.

[12] M. Luethi, U. Weidmann, and A. Nash, "Passenger arrival rates at public transport stations," in Proceedings of the 86th Annual Meeting of the Transportation, Washington, DC, USA, 2007.

[13] Y. Yan, Q. Meng, S. Wang, and X. Guo, "Robust optimization model of schedule design for a fixed bus route," Transportation Research Part C: Emerging Technologies, vol. 25, pp. 113-121, 2012.

[14] Y. D. Yan, Z. Y. Liu, Q. Meng, and Y. Jiang, "Robust optimization model of bus transit network design with stochastic travel time," Journal of Transportation Engineering, vol. 139, no. 6, pp. 625634, 2013.

[15] Z. Liu, Y. Yan, X. Qu, and Y. Zhang, "Bus stop-skipping scheme with random travel time," Transportation Research Part C: Emerging Technologies, vol. 35, pp. 46-56, 2013.

[16] Y. Li, X. C. Guo, and M. A. Montasir, "Evolution of the Chinese rural transit beyond emerging challenges," in Proceedings of the 89th Transportation Research Board Annual Meeting, Transportation Research Board, 2010.

[17] Kittelson \& Associates and KFH Group, "Transit capacity and quality of service manual-2nd edition," TCRP Report 100, Transportation Research Board, Washington, D. C., USA, 2003.

[18] E. D. Goldberg, Genetic Algorithms in Search Optimization and Machine Learning, Addison-Wesley, Reading, Mass, USA, 1989.

[19] L. Chambers, Practical Handbook of Genetic Algorithms: Applications, CRC Press, Boca Raton, Fla, USA, 1995.

[20] Z. Liu and Q. Meng, "Distributed computing approaches for large-scale probit-based stochastic user equilibrium problems," Journal of Advanced Transportation, vol. 47, no. 6, pp. 553-571, 2013. 


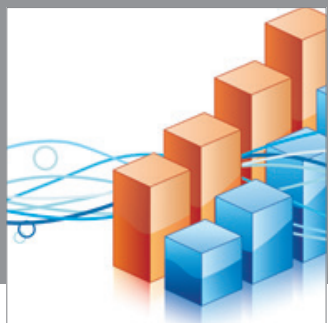

Advances in

Operations Research

mansans

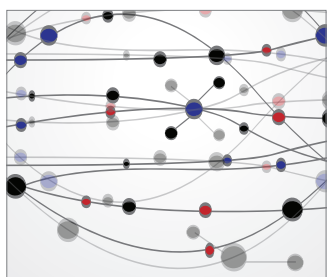

The Scientific World Journal
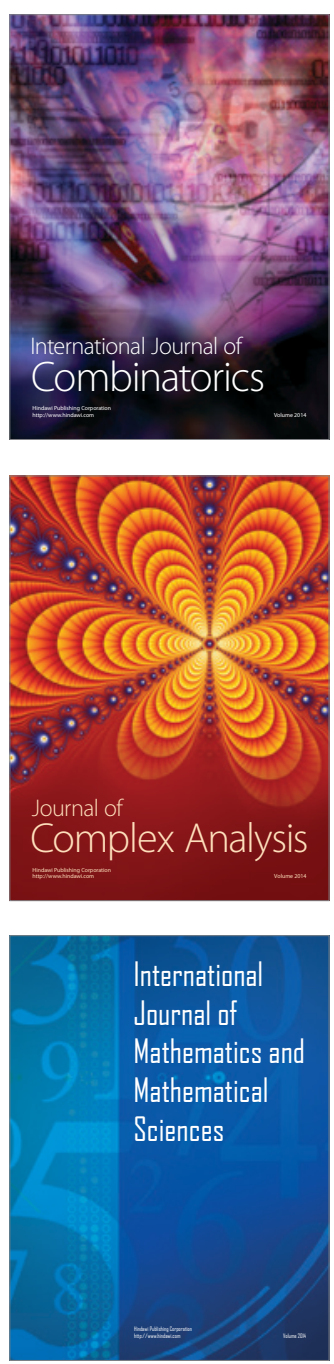
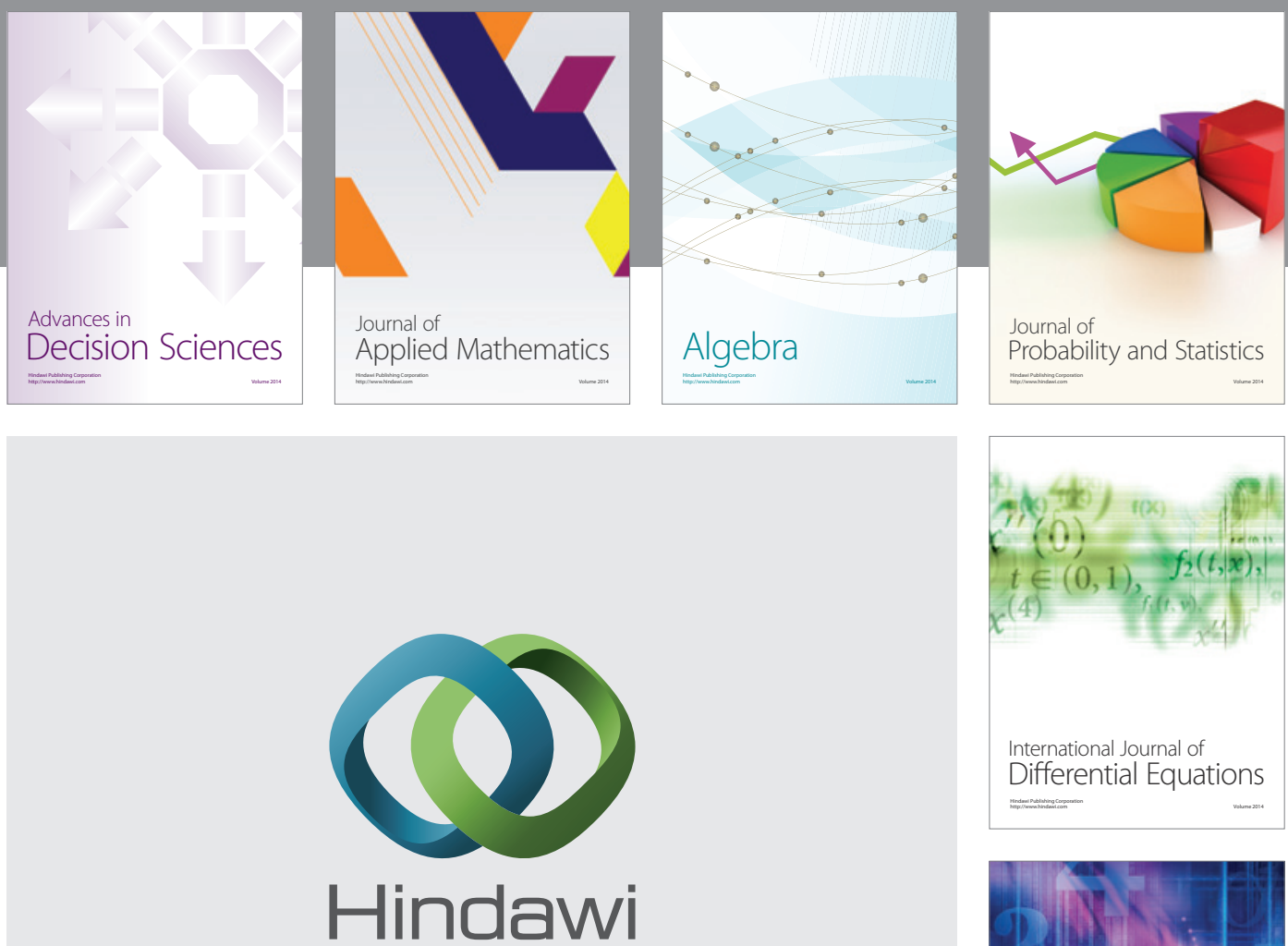

Submit your manuscripts at http://www.hindawi.com
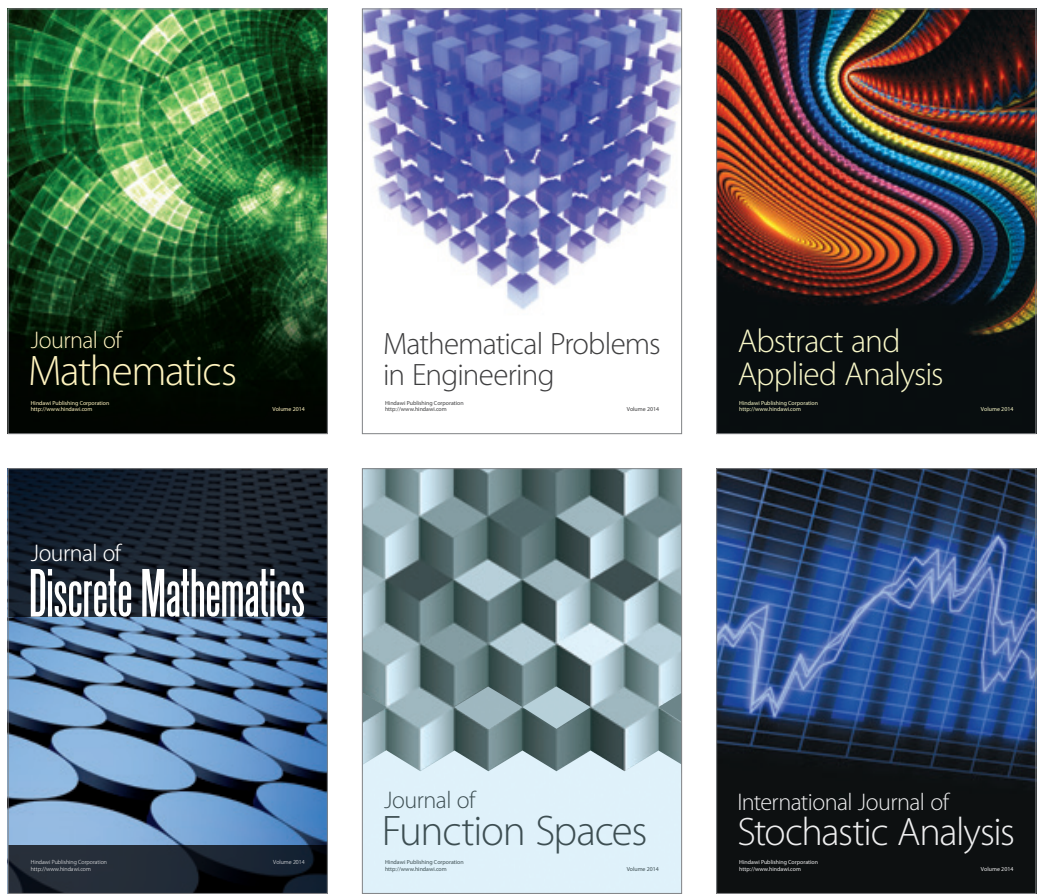

Journal of

Function Spaces

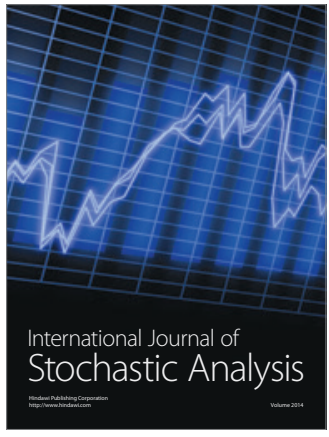

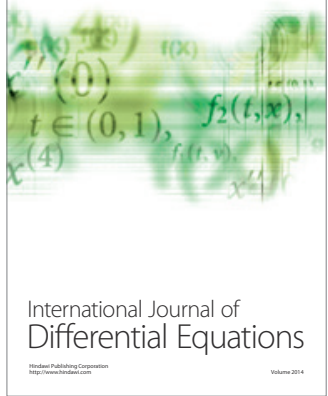
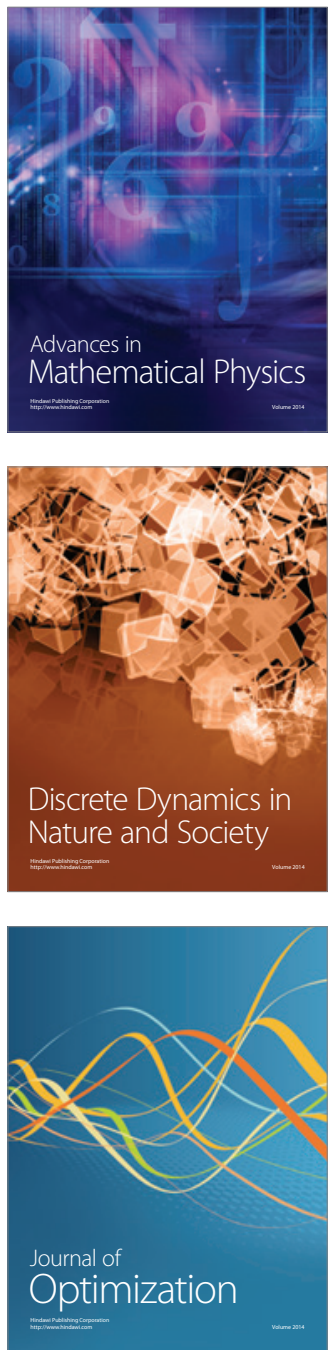